\title{
DEPOIMENTO ESPECIAL DE CRIANÇAS E ADOLESCENTES VÍTIMAS DE VIOLÊNCIA SEXUAL INTRAFẢMILIAR: ANÁLISE DO PROCEDIMENTO DIFERENCIADO DE OITIVA JUDICIAL PREVISTO NA LEI 13.431/17 FRENTE À GARANTIA DA PROTEÇÃO INTEGRAL
}

\author{
SPECIAL TESTIMONY OF CHILDREN AND ADOLESCENTS WHO \\ WERE VICTIMS OF INTRAFAMILIAL SEXUAL VIOLENCE: AN \\ ANALYSIS OF THE PARTICULAR JUDICIAL HEARING \\ PROCEDURE, AS PROVIDED FOR UNDER LAW NO. 13431/17 IN \\ RELATION TO THE GUARANTEE OF FULL PROTECTION
}

André Viana Custódio ${ }^{1}$

Bruna Katz ${ }^{2}$

\begin{abstract}
RESUMO
O presente artigo tem como objeto a análise do depoimento especial de crianças e adolescentes vítimas de violência sexual intrafamiliar frente à garantia da proteção integral. O problema que orienta a pesquisa é o seguinte: o procedimento diferenciado de oitiva judicial previsto na Lei 13.431/17, denominado depoimento especial, garante a proteção integral dos direitos de crianças e adolescentes, evitando a vitimização secundária nos casos de violência sexual intrafamiliar? Para responder a essa indagação, define-se como objetivo geral verificar se o depoimento especial é capaz de proteger integralmente os direitos de crianças e adolescentes vítimas de violência sexual intrafamiliar. Nos objetivos específicos, busca-se, inicialmente, analisar a proteção jurídica dos direitos de crianças adolescentes contra a violência. Posteriormente, contextualiza-se a violência sexual intrafamiliar contra crianças e adolescentes no Brasil. Por fim, objetiva-se demonstrar as consequências do depoimento especial na garantia de proteção integral às crianças e adolescentes vítimas de violência sexual intrafamiliar. $\mathrm{O}$ método de abordagem empregado é o dedutivo, enquanto o de procedimento é monográfico, com técnicas de pesquisa bibliográfica e documental. Conclui-se que o procedimento diferenciado de oitiva judicial previsto na Lei 13.431/17 não é capaz de proteger integralmente
\end{abstract}

\footnotetext{
1 Doutorado em Direito pela Universidade Federal de Santa Catarina (2006), Mestrado em Direito pela Universidade Federal de Santa Catarina (2002). Pós-doutorado pela Universidade de Sevilha/Espanha (2012). Atualmente é professor permanente e coordenador adjunto do Programa de Pós-Graduação em Direito - Mestrado e Doutorado - da Universidade de Santa Cruz do Sul. Líder do Grupo de Pesquisa Políticas Públicas de Inclusão Social e do Grupo de Estudos em Direitos Humanos de Crianças, Adolescentes e Jovens da UNISC, integrante do Núcleo de Estudos Jurídicos e Sociais da Criança e do Adolescente da Universidade Federal de Santa Catarina, Fellow da Ashoka desde 2002, também atua consultor na área de políticas públicas para infância e juventude, com especialidade nas áreas da prevenção e erradicação do trabalho infantil, atendimento socioeducativo, violência contra crianças e adolescentes, sistema de garantias de direitos e políticas públicas. andreviana.sc@gmail.com

${ }^{2}$ Mestranda em Direito pela Universidade de Santa Cruz do Sul (UNISC). Especialista em Direito de Família e Sucessões pela Fundação Escola Superior do Ministério Público (FMP). Especialista em Direito Processual Civil pela Universidade Federal do Rio Grande do Sul (UFRGS). Graduada pela Universidade do Vale do Rio dos Sinos (UNISINOS). Integrante do Grupo de Pesquisa Políticas Públicas de Inclusão Social e do Grupo de Estudos em Direitos Humanos de Crianças, Adolescentes e Jovens do PPGD/UNISC. Advogada atuante na área de Direito Privado, com ênfase em Direito de Família e Sucessões. Contato: contato@brunakatz.com.br.
} 
os direitos de crianças e adolescentes que sofreram violência sexual intrafamiliar, ensejando vitimização secundária e representando retrocesso com relação à teoria da proteção integral, por violar o princípio da não judicialização dos direitos de criança e adolescentes e reduzir o fenômeno da violência às práticas de responsabilização judicial.

\title{
PALAVRAS-CHAVE:
}

Criança. Adolescente. Depoimento Especial. Violência sexual intrafamiliar. Vitimização secundária.

\begin{abstract}
The present article aims to analyze the special testimony of children and adolescents subjected to intrafamilial sexual violence regarding the guarantee of full protection. The issue that guides this survey is: Can the particular judicial hearing procedure, as provided for under Law no. 13431/17, known as special testimony, ensure full protection of the rights of children and adolescents, preventing secondary victimization in cases of intrafamilial sexual violence? In order to answer this question, our general goal is to check whether special testimony can fully protect the rights of children and adolescents who were victims of intrafamilial sexual violence. Specific goals initially include an attempt to analyze legal protection of the rights of children and adolescents against violence. Subsequently, it aims to contextualize intrafamilial sexual violence against children and adolescents in Brazil. Finally, it intends to demonstrate the consequences of special testimony in relation to the guarantee of full protection to children and adolescents who were victims of intrafamilial sexual violence. Deduction is used at the approach method, while the procedural approach is monographic, relying on bibliographic and documental research techniques. It was concluded that the particular judicial hearing procedure set forth by Law no. 13431/17 is not capable of fully protecting the rights of children and adolescents who suffered intrafamilial sexual violence, triggering secondary victimization, and imposing a setback to the full protection theory, once it violates the principle of dejudicialization of children and adolescents' rights, and reduces the phenomenon of violence to legal liability practices.
\end{abstract}

\section{KEYWORDS:}

Child. Adolescent. Special testimony. Intrafamilial sexual violence. Secondary victimization.

\section{INTRODUÇÃO}

A violência sexual intrafamiliar constitui grave violação aos direitos humanos e fundamentais de crianças e adolescentes, desafiando o desenvolvimento de ações estratégicas de enfrentamento a estas práticas. Ao sistema de justiça caberá apurar a ocorrência da violência e responsabilizar o infrator, o que enseja a preocupação sobre a participação das vítimas nos atos processuais para que não sofram nova vitimização ao serem inquiridas sobre os fatos. 
A Lei n. 13.431, de 04 de abril de 2017 normatiza os procedimentos diferenciados de oitiva de crianças e adolescentes vítimas de violência, no intuito de propiciar uma escuta humanizada, que seja capaz de proteger os direitos da infância.

O presente artigo busca analisar o depoimento especial de crianças e adolescentes vítimas de violência sexual intrafamiliar frente à garantia da proteção integral. O objetivo geral é verificar se o procedimento diferenciado de oitiva judicial previsto na lei de depoimento especial é capaz de proteger integralmente os direitos de crianças e adolescentes vítimas de violência sexual.

Como objetivos específicos busca-se, inicialmente, analisar a proteção jurídica dos direitos de crianças e adolescentes contra a violência. Posteriormente, contextualiza-se a violência sexual intrafamiliar contra crianças e adolescentes no Brasil. Por fim, objetiva-se demonstrar as consequências do depoimento especial na garantia de proteção integral às crianças adolescentes vítimas de violência sexual intrafamiliar.

Essa construção orienta-se a partir do seguinte problema de pesquisa: o depoimento especial, previsto na Lei 13.431/17, garante a proteção integral de crianças e adolescentes, evitando a vitimização secundária nos casos de violência sexual intrafamiliar? Como hipótese, aponta-se que a referida legislação deixa de assegurar direitos fundamentais de crianças e adolescentes e enseja vitimização secundária, representando retrocesso com relação à teoria da proteção integral.

O referencial teórico para a pesquisa é a teoria da proteção integral. O método de abordagem empregado é o dedutivo, partindo-se da análise de premissas gerais para depois especificá-las. O método de procedimento é o monográfico, utilizando-se técnicas de pesquisa bibliográfica e documental.

O estudo justifica-se pela necessidade de aprofundamento do debate envolvendo os procedimentos diferenciados de escuta judicial de crianças e adolescentes que já tiveram seus direitos violados e dos riscos de vitimização secundária oriundo da investigação dos fatos, diante da recente edição da Lei 13.431/17, que normatiza os atos de oitiva.

Há relevância social na abordagem da questão, considerando o contexto da violência sexual intrafamiliar contra crianças e adolescentes no Brasil e as inúmeras consequências 
negativas que essa violação traz para as vítimas, na condição de sujeitos de direito em desenvolvimento, as quais podem ser agravadas em virtude da necessidade de relatar os fatos em juízo, tendo de revisitá-los.

Ao debater a respeito da importância do Sistema de Garantias de Direitos e da necessidade de integração das políticas públicas de justiça, pretende-se contribuir para a formulação e aprimoramento de políticas públicas relacionadas a garantia de direitos de crianças e adolescentes vítimas de violência sexual intrafamiliar.

Nesse contexto, procura-se contribuir para que soluções sejam encontradas, de forma a se garantir a concretização dos princípios da prioridade absoluta e do melhor interesse, evitando que crianças e adolescentes que já sofreram violência sexual intrafamiliar sejam revitimizadas.

\section{A PROTEÇÃO DOS DIREITOS DE CRIANÇAS E ADOLESCENTES CONTRA A VIOLÊNCIA.}

\subsection{A teoria da proteção integral}

A proteção jurídica dos direitos de crianças adolescentes no Brasil foi consolidada a partir da Constituição Federal de 1988, que adotou a teoria da proteção integral. A construção do marco teórico da proteção integral resulta de um processo histórico de reconhecimento da criança e do adolescente como sujeitos de direito, a merecerem proteção jurídica diferenciada, dada a sua especial condição de pessoas em desenvolvimento. (CUSTÓDIO, 2008, p. 32)

Essa concepção rompe com a doutrina da situação irregular, que vigorou durante todo o século XX e foi marcada pelo descaso, estigma e preconceito com relação à infância, possibilitando que diversas formas de violações de direitos fossem perpetradas. (CUSTÓDIO, REIS, 2017, p. 623-624).

Os Códigos de Menores de 1927 e 1979 expressavam a lógica da doutrina da situação irregular, em que a atenção do Estado se construía de forma desigual e a atuando com base no estigma da menoridade, considerando como “menores' aqueles em condição de pobreza, 
abandono ou maus tratos, bem como aqueles que praticavam infrações, sendo considerados em situação irregular, gerando riscos para a vida em sociedade, o que legitimava sua institucionalização. A atuação estatal, nesse contexto, era constituída por um misto de ações assistencialistas e repressivas. (CUSTÓDIO, 2008, p. 25/26)

A partir da década de 1980, com os movimentos sociais tendentes à redemocratização no Brasil, o olhar sobre a infância assume outros contornos, passando a haver preocupação com o atendimento dos interesses e proteção dos direitos de crianças e adolescentes (CUSTÓDIO, REIS, 2017, p. 634). O reconhecimento da dignidade da pessoa humana como fonte que orienta todo o ordenamento jurídico e da igualdade como princípio basilar na Constituição Federal de 1988 dão ensejo à proteção dos direitos fundamentais de todos os cidadãos, inclusive de crianças e adolescentes

No âmbito internacional, a Convenção sobre os Direitos da Criança de 1989 é um marco para a mudança de paradigma acerca do reconhecimento da condição de sujeitos de direitos às crianças e adolescentes, instituindo preceitos que deverão orientar a proteção dos seus direitos e exigindo dos países que a ratificaram a adoção de medidas para promovê-los. (VERONESE, 2013, p. 47).

O Brasil incorporou a Convenção ao ordenamento jurídico interno por meio do Decreto n. 99.710/90 (BRASIL, 1990a), tendo tal norma internacional impactado significativamente a proteção jurídica dos direitos de crianças e adolescente no ordenamento jurídico brasileiro e colaborado para a aprovação do Estatuto da Criança e do Adolescente através da Lei n. 8.069, de 13 de julho de 1990.

Na Constituição, o princípio da vinculação à teoria da proteção integral fica evidenciada no artigo 227, que atribui à família, à sociedade e ao Estado a responsabilidade de assegurar a proteção aos direitos fundamentais de crianças e adolescentes, com absoluta prioridade. Com isso, consagram-se, também, os princípios da prioridade absoluta e da tríplice responsabilidade compartilhada. (CUSTÓDIO, REIS, 2017, p. 634-635).

O Estatuto da Criança e do Adolescente (BRASIL,1990b) consolida, no âmbito da legislação ordinária, a teoria da proteção integral, regulamentando o texto constitucional, a fim de que seus preceitos possam ser efetivados (VERONESE, 2013, p. 50). No artigo $1^{\circ}$, assegura- 
se a proteção integral, ao passo que nos artigos e $3^{\circ}$ e $4^{\circ}$ são garantidos o tratamento diferenciado, em virtude da condição especial de sujeitos em desenvolvimento ostentada pelas crianças e adolescentes, a prioridade absoluta e a tríplice responsabilidade compartilhada.

A proteção integral constitui, assim, o fundamento de compreensão do Direito da Criança e do Adolescente, gerando uma nova estruturação jurídica, composta por princípios e regras que orientarão a busca pela efetivação dos direitos fundamentais da infância.

\subsection{A proteção jurídica nacional e internacional à criança e ao adolescente contra a violência.}

A violência contra crianças e adolescentes é um resquício da antiga concepção jurídica da situação irregular, em que o "menor" era inferiorizado e visto como um objeto de poder do adulto.

A despeito da proteção jurídica conferida a crianças e adolescentes a partir da teoria da proteção integral, as práticas de violência mantêm-se arraigadas na cultura, estando longe de serem superadas. (DIAS, CHAVES, 2016, p. 68)

No que diz respeito à proteção internacional contra a violência, a Convenção sobre Direitos das Crianças, ratificada pelo Brasil, impõe aos Estados Partes, em seu artigo $2^{\circ}$, que adotem as medidas necessárias para assegurar a proteção de crianças e adolescentes contra castigos em virtude de sua condição, estando implícita, aqui, a garantia contra a violência intrafamiliar. (BRASIL, 1990a)

O artigo 19, por sua vez, contém garantia de proteção contra todas as formas de violência, seja física, mental, negligência, maus tratos, exploração ou abuso sexual. Prevê tal dispositivo que caberá aos Estados Partes adotarem medidas protetivas contra a violência, por meio da elaboração de políticas públicas de atendimento, proteção e justiça (BRASIL, 1990a).

No que tange especificamente à violência sexual, o artigo 34 da Convenção determina que os países signatários se comprometam a adotar medidas capazes de colocar crianças e adolescentes a salvo de qualquer forma de exploração ou abuso sexual (BRASIL, 1990a). 
O artigo 39, por fim, contém previsão no sentido de que os Estados Partes promovam políticas públicas voltadas à recuperação física e psicológica e reintegração social de crianças e adolescentes vítimas de qualquer espécie de exploração, abuso, tortura ou tratamentos cruéis, desumanos ou degradantes (BRASIL 1990a)

Esse conjunto de normas determina aos países signatários, de forma cogente, que observem os postulados relacionados à proteção jurídica de crianças e adolescentes contra a violência, produzindo efeitos imediatos no ordenamento jurídico interno. (MOREIRA, JESUS, 2015, p. 4)

No âmbito da proteção constitucional, a Constituição Federal, ao inserir no art. 227 os princípios da proteção integral, da prioridade absoluta e da tríplice responsabilidade compartilhada, determina que deve haver medidas prioritárias de enfrentamento à violência contra a criança e o adolescente, a serem asseguradas pela família, sociedade e Estado. (BRASIL, 1988).

O Estatuto da Criança e do Adolescente também contém dispositivos que protegem, de forma direta ou indireta, as crianças contra a violência. Os artigos $1^{\circ}$ e $4^{\circ}$ garantem a proteção integral, assegurando os direitos fundamentais à saúde, dignidade, liberdade e convivência familiar, os quais serão inexoravelmente afetados pela prática de atos de violência durante da infância. $\mathrm{O}$ artigo $5^{\circ}$, por seu turno, prevê expressamente que crianças e adolescentes devem estar a salvo de toda forma de violência, negligência, exploração, crueldade ou opressão. $\mathrm{O}$ artigo $7^{\circ}$, finalmente, trata do direito à vida digna e à saúde, requisitos essenciais ao desenvolvimento sadio. No que diz respeito à prevenção e à política de atendimento nos casos de violência, estão disciplinadas nos artigos 70 e 86, III. (BRASIL, 1990b)

Especificamente no que diz respeito à violência física e psicológica intrafamiliar, a Lei 13.010/14 alterou o Estatuto da Criança e do Adolescente, para estabelecer o direito de crianças adolescentes serem educados sem o uso de castigos físicos ou tratamento cruel ou degradante, colocando-os a salvo de práticas que possam gerar sofrimento físico, humilhações, ameaças e submissão a ridículo. A referida lei incluiu dispositivos no Estatuto e alterou outros, para responsabilizar os pais que utilizem castigos imoderados, sujeitando-os a sanções, além de referendar as medidas de proteção a serem adotadas pelos Conselhos Tutelares. (BRASIL, 2014) 
Recentemente introduzida no ordenamento jurídico, a Lei 13.431/2017 foi editada com a finalidade de estabelecer diretrizes para a oitiva de crianças adolescentes vítimas ou testemunhas de violência, ao mesmo tempo em que cria mecanismos para coibi-la. A legislação reforça a garantia de proteção dos direitos fundamentais de crianças e adolescentes já previstas em outras normas nacionais e internacionais e, em seu artigo $2^{\circ}$, contempla a obrigação dos entes públicos federados de desenvolver ações integradas com o escopo de resguardar crianças e adolescentes de toda a forma de negligência, discriminação, exploração, violência, abuso, crueldade e opressão. (BRASIL, 2017)

Afora isso, essa legislação prevê, em seu artigo $4^{\circ}$, as formas de violência contra a criança e o adolescente, sem excluir outras condutas criminosas já tipificadas. Para os efeitos da lei, as violências contra crianças e adolescentes podem ser: física, que ofende a integridade física ou a saúde corporal da criança e do adolescente; psicológica, que abrange discriminação, depreciação e desrespeito e inclui, no âmbito intrafamiliar, atos de alienação parental e condutas que exponham crianças ou adolescentes, direta ou indiretamente, a crimes violentos praticados contra membros de sua família ou rede de apoio; sexual, entendida qualquer conduta que constranja a criança ou o adolescente a presenciar conjunção carnal ou qualquer outro ato libidinoso e institucional, entendida como aquela praticada por uma instituição pública ou conveniada, inclusive nas hipóteses em que ensejar vitimização secundária. (BRASIL, 2017)

Esse conjunto de normas consolida a proteção jurídica de crianças e adolescentes contra todas as formas de violência, orientando o Estado a promover políticas públicas tendentes ao seu enfrentamento.

\subsection{O Sistema de Garantias de Direitos no enfrentamento à violência contra crianças e adolescentes}

O combate à violência contra crianças e adolescentes ocorre por meio da coordenação de políticas públicas diversas, intersetoriais e realizadas de modo articulado pela rede de atendimento, proteção e justiça constituindo o Sistema de Garantias de Direitos. (MOREIRA, REIS, 2016, p. 80) 
Esse sistema se estrutura por meio do compartilhamento de responsabilidades, atribuições e competências entre instituições públicas e privadas, na forma do artigo 86 do Estatuto da Criança e do Adolescente. Por meio da articulação de políticas públicas, visa a garantir atendimento, justiça, proteção e promoção de direitos às crianças e adolescentes. (SOUZA, 2016, p. 80-81)

As ações estratégicas de enfrentamento à violência infantil devem ocorrer em diversos níveis de atuação e de forma descentralizada nos municípios, devendo os órgãos que compõe o sistema realizar um trabalho em rede, com a cooperação dos atores envolvidos, a fim de que seja garantida a proteção dos direitos fundamentais das crianças e adolescentes.

O primeiro nível de políticas públicas é o de atendimento, a ser planejado estrategicamente pelos Conselhos de Direitos das Crianças e Adolescentes junto à rede de atendimento e as comunidades, no sentido de promover ações de sensibilização, na busca pela paulatina superação dos resquícios culturais que, historicamente reproduzidos, ensejam violência contra crianças e adolescentes. A atuação deve envolver, também, a capacitação das equipes técnicas responsáveis pelo atendimento e a estruturação dos serviços especializados de atendimento. (CUSTÓDIO, MOREIRA, 2019, p. 139)

Os Conselhos de Direitos da Criança e do Adolescente estão instituídos nas esferas nacional, estadual e municipal e possuem atribuições de formular, deliberar e controlar as políticas públicas em todos os níveis para a garantia de direitos. Deles participam entidades da sociedade civil e representantes governamentais. (SOUZA, 2016, p. 88)

O segundo nível se situa nas políticas públicas de proteção, com o objetivo de enfrentar ameaças ou violações de direitos de crianças e adolescentes. Nele atuam os Conselhos Tutelares e o Ministério Público, voltando-se as ações, nessa etapa, exclusivamente à esfera extrajudicial.

O Conselho Tutelar é órgão autônomo, colegiado, municipal e não jurisdicional, atuando sem pretensão de julgar conflitos, no exclusivo intuito de proteger os direitos de crianças e adolescentes, quando ameaçados ou violados aplicando medidas de caráter administrativo.

Em se tratando de situações envolvam violência contra crianças e adolescentes, o Conselho Tutelar exerce importante papel, cabendo-lhe, ao receber queixas, denúncias ou 
solicitações, averiguar os fatos, orientar os pais ou responsáveis e, sendo o caso, aplicar as medidas administrativas de proteção pertinentes, arroladas nos artigos 101 e 129 do Estatuto da Criança e do Adolescente. (SOUZA, 2016, p. 97).

Nos casos de violência intrafamiliar praticada pelos próprios pais ou responsáveis, as medidas de proteção que vão desde a aplicação de medidas de proteção pelo Conselho Tutelar como o encaminhamento aos serviços de atendimento, tratamento psicológico ou psiquiátrico, até a aplicação de medidas judiciais como a perda da guarda ou a destituição do poder familiar, a depender das características da violação praticada.

Por fim, o terceiro nível é aquele que ocorre por meio da política de justiça, sendo exercido pela Defensoria Pública, Ministério Público e Poder Judiciário, cabendo-lhes realizar a responsabilização pelas violações praticadas pela ação ou omissão da sociedade, família ou Estado, voltando suas ações para a proteção e efetivação de direitos de crianças e adolescentes (CUSTÓDIO, MOREIRA, 2019, p. 139-140)

As ações do sistema de justiça devem ocorrer sem o intervencionismo de outrora, quando vigia a doutrina da situação irregular. Tendo sofrido reordenamento institucional pela teoria da proteção integral, esse sistema atuará forma suplementar, com o escopo de salvaguardar os direitos violados de crianças e adolescentes, quando estes não puderem ser providos de forma suficiente pelos órgãos administrativos de proteção. (SOUZA, 2016, p. 101).

A política de justiça consistirá, portanto, na última instância voltada à garantia de proteção e efetivação dos direitos de crianças e adolescentes.

\section{A VIOLENCIA SEXUAL INTRAFAMILIAR CONTRA CRIANÇAS E ADOLESCENTES}

\subsection{Formas de violência sexual contra crianças e adolescentes}


A violência sexual contra crianças e adolescentes pode se manifestar de diferentes formas, tratando-se de um fenômeno multifacetado, que assume dinâmicas variáveis conforme o contexto no qual ocorre.

Para a Organização Mundial da Saúde, a violência sexual define-se como a tentativa de obtenção de um ato de natureza sexual por coação, que pode ocorrer por meio de comentários, investidas e outras atitudes indesejadas, como força física, ameaças, intimidação psicológica. Compreende, também, aquelas situações em que, mesmo não havendo coação propriamente dita, a pessoa agredida é incapaz de consentir ou compreender a situação na qual está inserida. (KRUG, et al, 2002, p. 147)

A agressão sexual, portanto, não deriva exclusivamente de contato físico, podendo envolver muitas outras situações. Em se tratando de violência sexual perpetrada contra criança ou adolescente, importa verificar a posição de desigualdade e dominação imposta pelo adulto, a qual impede que a vítima tenha completa consciência das consequências da interação sexual provocada, o que pode ocorrer por meio de constrangimento, insinuação, sedução ou utilização da figura da autoridade. (KÜHL, 2018, p. 79-80)

Trata-se de envolver sujeitos em desenvolvimento em situações sexuais, sem que as vítimas tenham maturidade suficiente para compreender ou consentir com o ato. (AZAMBUJA, 2006, p. 425). Em se tratando de crianças e adolescentes, não se pode falar em consenso, já que lhes falta compreensão, estando submetidos à vontade do agressor, adulto em posição de dominação.

\footnotetext{
O consentimento implica em acordar, autorizar, aprovar, dar permissão, todavia, o consentimento também implica na necessidade de que a pessoa possui todas informações necessárias para compreender plenamente a situação, isto é, estar consciente sobre o propósito de sua participação e as consequências delas. Desta forma, o consentimento não se enquadra com violência sexual infantil, pois a criança e o adolescente estão submetidos à vontade de quem o abusa, o qual utiliza sua autoridade sobre a criança ou adolescente, através das diversas formas de coerção e também utiliza-se da impossibilidade da vítima de ter consciência plena sobre a violência. (KÜHL, 2018, p. 81)
}

Veja-se que o Código Penal considera crimes sexuais contra vulnerável os praticados contra vítimas até quatorze anos. Isso ocorre diante da presunção de que, nessa idade, a vítima não tem a compreensão necessária para consentir. (BRASIL, 1940) Quando se tratar de adolescente com quatorze anos completos, a legislação penal não presume de modo absoluto a violência sexual, o que não impede que a coerção possa ser demonstrada conforme as 
circunstâncias do caso concreto, sempre levando em conta a já mencionada relação de dominação entre o agressor e a vítima.

Assim, a Lei 13.431/17, para além de conceituar a violência sexual contra crianças e adolescentes, subdividiu as situações de violência em abuso, exploração sexual e tráfico de pessoas. (BRASIL, 2017)

Nos termos da referida legislação, o abuso sexual será entendido a ação que utiliza a criança para fins sexuais, seja conjunção carnal ou outro ato libidinoso, podendo ser realizado de modo presencial ou por meio eletrônico, com a finalidade de estimular sexualmente o agente ou terceiro, incluído nesse conceito a exposição do corpo em vídeos ou fotos. (BRASIL, 2017).

Vale ressaltar, portanto, que o abuso não exige contato físico, podendo ocorrer por meio de telefonemas obscenos, estimulação verbal sobre atividades sexuais, exibição de material pornográfico à criança, tudo no intuito de despertar o interesse sexual da criança ou adolescente.

A exploração sexual, por seu turno, ocorrerá quando a criança for usada em atividade sexual em troca de remuneração ou outras formas de compensação, tanto de forma independente, como sob patrocínio, apoio ou incentivo de terceiro. Por fim, quanto ao tráfico de pessoa, compreenderá recrutamento, transporte, transferência, alojamento ou o acolhimento da criança ou do adolescente, dentro do território nacional ou para o estrangeiro, com o fim de exploração sexual, mediante ameaça, uso de força ou outra forma de coação, rapto, fraude, engano, abuso de autoridade, aproveitando-se da sua vulnerabilidade ou entrega ou aceitação de pagamento. (BRASIL, 2017)

A violência sexual intrafamiliar contra crianças e adolescentes se caracteriza pela relação havida entre a vítima e o agressor, ao conviverem no mesmo espaço doméstico. Ocorre, portanto, no ambiente familiar, não necessariamente perpetrada por membros da família natural, mas também por responsáveis legais, parentes por afinidade ou membros da família extensa, mesmo que a convivência seja esporádica. (MINISTÉRIO DA SAÚDE, 2002).

Nessas situações, o adulto vale-se da proximidade com a criança ou adolescente para obter a vantagem sexual. Assim, à falta de condições cognitivas da vítima para compreender adequadamente o ato soma-se mais um fator que dificulta a resistência, qual seja a relação de 
hierarquia, dependência, confiança ou afeto com o agressor. Daí porque se diz que a violência sexual intrafamiliar é uma das piores formas de violação dos direitos de crianças e adolescentes.

\subsection{Causas e consequências da violência sexual intrafamiliar contra crianças e adolescentes.}

A violência sexual contra crianças e adolescentes é um problema complexo e multifatorial, com consequências nefastas para as vítimas, afetando inúmeras áreas de seu desenvolvimento. Quando ocorre no âmbito da família, praticada por pessoas nas quais as vítimas confiam, dependem e pelas quais deveriam ser protegidas, os danos tendem a ser ainda mais expressivos.

Não há como se apontar uma causa única para a violência sexual no âmbito familiar, até mesmo em decorrência da multiplicidade de pessoas que podem vir a praticar a agressão dentro da família, bem como pelas diferentes condições socioeconômicas e culturais dos núcleos familiares em que a violação ocorre. Importa destacar, aqui, que a violência intrafamiliar acontece em todas as classes sociais, embora nas mais altas a visibilidade seja menor.

Historicamente, padrões culturais contribuíram para que crianças e adolescentes fossem inferiorizados, tratados com descaso, autoritarismo e violência, sendo comum que pais impusessem aos filhos uma educação repressiva e violadora de direitos. (DIAS, CHAVES, 2016, p. 57)

Os resquícios culturais da concepção menorista fazem com que parte da sociedade continue enxergando a criança e o adolescente como um objeto de dominação, especialmente nas relações mais íntimas. Em sendo assim, a violência sexual constitui uma das formas pelas quais essa ideia de exercício de poder intergeracional se exterioriza.

A coisificação das crianças e adolescentes, aliada ao adultocentrismo, concepção que vê o adulto como centro de tudo, leva à crença de que as crianças podem ser exploradas para a satisfação dos desejos dos adultos, inclusive sexuais. (MOREIRA, REIS, 2016, p. 88-89). 
Afora isso, a extrema pobreza e seus subprodutos também podem ser fatores que desencadeiam violência intrafamiliar. A falta de moradia adequada, de privacidade, trabalho, acesso à saúde e à educação fragilizam socialmente a família, abrindo espaço para violações. (MOREIRA, REIS, 2016, p. 84)

Outros aspectos relacionados ao agressor, como abuso de álcool ou drogas, doenças mentais ou psíquicas e histórico de abuso familiar podem ser apontados como possíveis causas para a violência sexual intrafamiliar (KÜHL, 2018, p 99).

A agressão sexual praticada contra crianças e adolescentes por membros da família gera consequências em diversas esferas da vida da vítima, tendo em vista sua condição de sujeitos em desenvolvimento físico, mental e psicossocial.

As consequências físicas da agressão sexual são inúmeras e variáveis, podendo ir desde hematomas, lesões, mutilação, contração de doenças sexualmente transmissíveis, até a morte.

No campo do comportamento, trata-se de uma experiência que as crianças e adolescentes têm extrema dificuldade de assimilar ou denunciar, pela ausência de maturidade suficiente para compreender a dinâmica e gravidade dos fatos. Os vínculos de afeto e confiança com o agressor ensejam sentimentos contraditórios, de culpa e receio dos desdobramentos da revelação, seja pelo possível descrédito na sua palavra ou pela chance de que o familiar venha a ser afastado do convívio com o infante. (VEIGA, CHAVES, 2016, p. 64)

As consequências psíquicas variam de pessoa para pessoa e podem se manifestar a longo prazo, sendo as expressões mais comuns o medo, ansiedade, a culpa, raiva e a tristeza. É possível que haja, também, comportamentos agressivos, hiperssexualizados, isolamento social, abuso de álcool e outras substâncias. (KÜHL, 2018, p. 95).

O trauma se faz e se guarda como sofrimento, como perda de si, como exclusão de
possibilidades, e pode se mostrar em raiva ou em feridas psicossomáticas muito
diversas de pessoa a pessoa. Teicher (2002) assinala que, do ponto de vista da
neurobiologia, o abuso deixa também marcas indeléveis no cérebro devido ao estresse
experimentado. (FALEIROS, 2005, p. 69)

A violação de direitos de crianças e adolescentes por meio da violência sexual intrafamiliar gera danos imensuráveis à saúde física e mental, com traumas que poderão afetálos por longo período, quiçá por toda vida. 


\subsection{Dados sobre a violência sexual intrafamiliar no Brasil}

A violência sexual contra crianças e adolescentes deve ser obrigatoriamente notificada quando chegar ao conhecimento de quaisquer dos órgãos que compõem a rede de atendimento ou do sistema de garantias de direitos.

A análise de dados é importante para que se estabeleçam ações estratégicas de combate à violência, a partir da compreensão das circunstâncias em que a violação ocorreu, perfil das vítimas e agressores e avaliação das situações que podem aumentar o risco.

Em se tratando de violência perpetrada no ambiente familiar, não se pode olvidar que inúmeros casos sequer chegam ao conhecimento dos órgãos executores de políticas públicas, seja pela falta de compreensão das vítimas, por medo ou vergonha. Assim, inúmeras situações de violência sexual intrafamiliar contra crianças e adolescentes permanecem na clandestinidade. (KÜHL, 2018, p. 90).

O Ministério da Mulher, Família e Direitos Humanos divulgou dados relativos ao serviço de ouvidoria que disponibiliza, em que casos envolvendo violações de direitos humanos podem ser reportados por telefone. A partir das informações, verifica-se que, no ano de 2019, foram registradas 86.837 denúncias envolvendo violações de direitos de crianças e adolescentes, das quais $11 \%$ são relativas à violência sexual, o que corresponde a 17.029 casos relatados. (BRASIL, 2020, p. 35; 44).

As violações identificadas no âmbito do Sistema Único de Saúde (SUS) são disponibilizados pelo Sistema de Agravos de Notificação (SINAN), órgão pertencente ao Ministério da Saúde. A comunicação é compulsória, devendo ser realizada sempre que as equipes técnicas identifiquem indícios de violência. (CUSTÓDIO, MOREIRA, 2019, p. 133)

O Mapa da Violência contra Crianças e Adolescentes, fruto de pesquisa realizada a partir dos dados SINAN do ano de 2011, demonstra os atendimentos às vítimas de violência no âmbito do Sistema Único de Saúde.

Da totalidade dos 33.327 casos de violência notificados, 19,9\% diziam respeito à violência sexual, o que corresponde a 10.425 ocorrências, posicionando a agressão sexual como a segunda maior forma de violação, atrás apenas da física, que atingiu a marca de $40,5 \%$ dos 
casos, equivalente a 21.279 ocorrências. No mais, $17 \%$ dos casos reportados eram de violência moral (8.948), 15,8\% de abandono (8.275), 4,5\% outras formas de violência não especificadas (2.596) e 1,9\% de tortura (922). (WAISELFISZ, 2012, p. 67)

Dentre as vítimas de violência sexual, 83\% (8.677) são do sexo feminino. Quanto ao agressor sexual, 10,2\% são o pai (1.056), 10,3\% são o padrasto (1.061), 2\% são a mãe (231), 0,2\% são a madrasta (23), 2,6\% são irmãos (269), 0,9\% são o cônjuge (98), 0,2\% são o excônjuge (17), 6,3\% são o namorado (647), 0,8\% são o ex-namorado (84). Os demais casos foram praticados por pessoas estranhas à família. (WAISELFISZ, 2012, p. 72-73).

Esses dados demonstram, em primeiro lugar, que a violência sexual ocupa uma posição de destaque dentre as formas de violências praticadas contra crianças e adolescentes, com o percentual significativo de ocorrências frente à totalidade de casos.

Evidenciam, ademais, que muitas das violações sexuais acontecem dentro do ambiente familiar, não se devendo perder de vista que esse número representa apenas parte da realidade, já que as agressões perpetradas por membros da família nem sempre são levadas ao conhecimento da rede de proteção à criança e ao adolescente.

\section{O DEPOIMENTO ESPECIAL DE CRIANÇAS ADOLESCENTES VÍTIMAS DE VIOLÊNCIA SEXUAL INTRAFAMILIAR E SUAS CONSEQUÊNCIAS FRENTE À GARANTIA DA PROTEÇÃO INTEGRAL.}

\subsection{A Lei 13.431/17 e a pretensão de humanizar a escuta judicial de crianças e adolescentes.}

A violação de direitos de crianças e adolescentes impõe que se adotem medidas interdisciplinares de enfrentamento à violência sofrida, a partir de políticas públicas de atendimento, proteção e justiça. 
Quando a violação demanda a atuação do Poder Judiciário, com o intuito de apurar a prática da violência e imputar responsabilidade ao agressor, surge a preocupação com a forma como as vítimas, sujeitos em desenvolvimento, serão recepcionadas pelo sistema de justiça.

A Lei 13.431/17 foi criada com a pretensão de humanizar a escuta e proteger os direitos de crianças e adolescentes vítimas ou testemunha de violência, por meio da normatização de procedimentos diferenciados de oitiva judicial e extrajudicial.

A matéria não é propriamente uma novidade no Brasil. Há tempos existe regulamentação acerca da adoção de procedimentos específicos para a oitiva judicial de crianças e adolescentes, embora antes estivesse limitada à esfera administrativa.

No ano de 2003, o Tribunal de Justiça do Rio Grande do Sul lançou projeto pioneiro com essa finalidade, denominado "Depoimento sem Dano", o qual foi regulamentado institucionalmente no âmbito da sua jurisdição. (SANTOS, COIMBRA, 2017, p. 596). As principais providências consistiram na criação de ambientes diferenciados para a realização dos atos de oitiva, separados das salas comuns de audiência, com a intenção de ofertar à criança maior privacidade e acolhimento.

A ideia acabou replicada por outras unidades judiciárias do país, até que o Conselho Nacional de Justiça a regulamentou, por meio da Recomendação n. 33/2010, orientando os tribunais de justiça a implantarem sistemas de depoimento videogravado para crianças e adolescentes, a ser realizado em ambiente próprio e com o acompanhamento de um profissional para atuar conjuntamente na referida prática. Dentre as recomendações, estava a de que os participantes da escuta judicial fossem capacitados para o emprego de técnicas adequadas de entrevista cognitiva, bem como que os serviços do sistema de justiça estivessem aptos a apoiar emocionalmente a criança e o adolescente, durante e após o procedimento. (CONSELHO NACIONAL DE JUSTIÇA, 2010).

Na Lei 13.431/17, duas modalidades distintas de oitiva são instituídas: a escuta especializada, realizada perante os órgãos de proteção, e o depoimento sem dano, que ocorre perante a autoridade policial ou judiciária. A escuta especializada consistirá em entrevista sobre a situação de violência, limitando-se o relato ao estritamente necessário para o cumprimento de 
sua finalidade. O depoimento especial, por sua vez, exigirá do sistema de justiça a observância de uma série de diretrizes previstas na lei. (BRASIL, 2017)

No que diz respeito à oitiva realizada em âmbito judicial, que constitui objeto do presente estudo, a nova legislação garante às vítimas ou testemunhas que não venham a ter qualquer tipo de contato com o acusado ou com outras pessoas que possam representar ameaça. Há, também, determinação no sentido de que os depoimentos devam ser colhidos em ambiente adequado, garantindo-se a privacidade às crianças e adolescentes, com intuito de propiciar o seu acolhimento. (BRASIL, 2017)

Ainda, regulamenta a lei que o depoimento, sempre que possível, será realizado uma só vez. A regra, contudo, poderá ser mitigada se preenchidos os seguintes requisitos, de forma cumulativa: a autoridade judicial justificar a imprescindibilidade e houver concordância da vítima ou de seu representante legal. (BRASIL, 2017)

Quanto aos protocolos de oitiva, encontram-se disciplinados no artigo 12 da Lei 13.431/17. De início, exige-se que os profissionais especializados esclareçam à criança ou adolescente sobre os procedimentos do depoimento especial, informando-lhes acerca dos seus direitos. Assegura-se aos depoentes que realizem narrativa livre dos fatos, com possibilidade de intervenção do profissional especializado, quando necessário. O depoimento será transmitido em tempo real na sala de audiências e permanecerá gravado em áudio e vídeo, garantindo-se o sigilo. Caberá ao magistrado avaliar a pertinência de perguntas, que poderão ser transmitidas à criança ou adolescente por meio do profissional especializado, com as adaptações necessárias. (BRASIL, 2017).

A ideia do uso dos profissionais especializados - ainda que a lei não especifique qual é a especialidade exigida - é a de que atuem como intermediários entre a criança ou adolescente e o juiz, com o cuidado e acolhimento necessários para que as informações fluam de forma mais espontânea. (SANTOS, COIMBRA, 2017, p. 597).

\subsection{A regulamentação do depoimento especial por meio da Resolução n. 299/19 do Conselho Nacional de Justiça}


Antes mesmo da entrada em vigor da Lei 13.431/17, havia grande controvérsia em torno dos procedimentos diferenciados de oitiva de crianças e adolescentes vítimas de violência, inicialmente regulamentados no âmbito das competências internas dos tribunais de justiça e, depois, pela Recomendação n. 33 do Conselho Nacional de Justiça.

De um lado, estavam aqueles que defendiam ser impositiva a regulamentação de técnicas capazes de propiciar uma escuta humanizada no âmbito do Poder Judiciário, entendendo que tais práticas contribuíam para assegurar o melhor interesse de crianças e adolescentes. Para essa corrente, crianças e adolescentes teriam o direito de ser ouvidas nos processos que envolvessem seus interesses. Impedi-las de participar poderia, inclusive, gerar sentimentos de menos valia pela violência sofrida, como se o adulto não tivesse interesse em conhecer a história da criança ou não acreditasse nela. (CEZAR, 2014, p. 260)

De outro, os que se posicionavam no sentido que o procedimento continha inúmeras falhas e, a despeito da regulamentação, seguia gerando vitimização secundária, por considerar a criança um mero instrumento para a obtenção de provas, o que ensejou inúmeras manifestações contrárias à implementação do então chamado depoimento sem dano, por conselhos de classe de psicologia e serviço social. (MÖLLER, DINIZ, 2018, p. 2-4)

Com a superveniência da Lei 13.431/17, a polarização seguiu existindo, acentuando-se as críticas em torno do procedimento diferenciado de oitiva (CONSELHO FEDERAL DE PSICOLOGIA, 2018, p. 6-7), em virtude das lacunas legislativas que deixariam importantes definições acerca do procedimento de depoimentos especial, como por exemplo, a respeito dos protocolos de oitiva a serem aplicadas. Isso permitiria que o juiz ou o próprio profissional agissem com discricionariedade na condução do depoimento, abrindo espaço para a violação de direitos de crianças e adolescentes. (PEREIRA JÚNIOR, REBOUÇAS, PEREIRA, 2018, p. 413-414)

Transcorridos cerca de seis meses da entrada em vigor da Lei 13.431/17, o Conselho Nacional de Justiça editou novo ato administrativo, qual seja a Resolução 299, de 05 de novembro de 2019, com o intuito de regulamentar a referida lei, instituindo uma série de diretrizes que deverão ser observadas pelos tribunais estaduais e federais. 
Dentre as previsões, destaca-se a obrigatoriedade de que todas as comarcas do território nacional implantem salas de depoimento especial, bem como de que haja transmissão on-line do ato à sala de audiências. Ainda, incumbiu-se os tribunais de realizar a capacitação dos servidores, profissionais especializados e magistrados para o depoimento especial, determinando-se que os profissionais especializados que atuarão na tomada do depoimento deverão ser, preferencialmente, aqueles que já integram o quadro de servidores das unidades judiciárias. (CONSELHO NACIONAL DE JUSTIÇA, 2019).

Quanto ao uso das imagens e vídeos dos depoimentos já realizados para fins de treinamento dos profissionais e magistrados, restou condicionada à autorização, a ser dada pela criança ou adolescente ou por seus responsáveis. No mais, foram reforçadas disposições já constantes da Lei 13.431/17, como o direito da criança a permanecer em silêncio e de ser informada sobre seus direitos. No que tange ao protocolo de oitiva, ressalvou-se que deve ser validado cientificamente, incumbindo ao magistrado zelar pela sua observância. (CONSELHO NACIONAL DE JUSTIÇA, 2019)

Com a publicação deste ato, houve nova manifestação por parte do Conselho Federal do Serviço Social, por meio de nota pública, em que reitera seu posicionamento contrário às práticas envolvendo o depoimento especial, especialmente porque a resolução preconiza que os profissionais especializados devem ser, preferencialmente, os integrantes dos quadros de pessoal dos tribunais, os quais são compostos, em maioria, por assistentes sociais, não estando entre as atribuições da classe a inquirição com base em técnicas e procedimentos investigativos estranhos às suas competências. (CONSELHO FEDERAL DO SERVIÇO SOCIAL, 2020).

Vê-se, assim, que mesmo com a normatização do depoimento especial por meio da Lei 13.431/17 e, inclusive, sua posterior regulamentação por ato do Conselho Nacional de Justiça, permaneceram hígidas as críticas que já vinham sendo feitas antes da edição da lei, com o fundamento principal de que se trataria de procedimento potencialmente causador de nova vitimização às crianças e adolescentes.

\subsection{O depoimento sem dano e a vitimização secundária de crianças e adolescentes vítimas violência sexual intrafamiliar}


A violência sexual intrafamiliar contra crianças e adolescentes, por suas particularidades, apresenta considerável dificuldade de identificação e intervenção, exigindo atendimento cuidadoso e especializado pelos diferentes órgãos do Sistema de Garantias de Direitos.

Em muitos casos, essa espécie de violação não deixa marcas aparentes, havendo, ainda, uma dinâmica complexa entre a vítima, o abusador e os demais membros da família, em que silêncio e o segredo revelam-se como elementos centrais. (FALEIROS, p. 71-72)

O sistema de justiça, diante da escassez de elementos probatórios que viabilizem a apuração dos fatos e a possível responsabilização do acusado, dá especial valor à palavra da vítima. Com isso, acaba-se atribuindo à criança ou adolescente a tarefa de esclarecer os fatos, no intuito de que sejam fornecidas provas ao juízo. Essa inquirição é potencialmente desencadeadora de sofrimento à vítima, por expô-la a constrangimento, mediante a exigência de que relate detalhadamente a violência sofrida.

Nisto consiste chamada vitimização secundária: a criança, que já foi submetida à violência sexual intrafamiliar, denominada vitimização primária, torna a ser vítima, agora de outra violação, produzida institucionalmente pelo sistema de justiça na busca de provas, o que dificulta enormemente a superação do trauma decorrente da violência. (BITENCOURT, 2007, p. 11)

A questão especial ganha relevo quando se considera a peculiar condição de sujeito em desenvolvimento ostentada pela criança ou adolescente, o que não possui maturidade suficiente compreender as implicações de suas manifestações. (AZAMBUJA, 2013, p. 490-492)

Exigir que a criança ou adolescente elucide os fatos ao juízo pode trazer graves consequências. Na hipótese de uma sentença condenatória, poderá sentir-se responsável pela sanção aplicada ao seu familiar. De outro norte, caso a sentença seja de improcedência, é possível que a situação gere sentimento de culpa, por supostamente haver desencadeado uma investigação baseada em mentiras. (MÖLLER, DINIZ, 2018, p. 13)

A Lei 13.431/17, ao disciplinar o procedimento de escuta de crianças e adolescentes vítimas de violência em âmbito judicial, criando regras que deverão ser necessariamente 
observadas em tais atos, dá especial relevo à responsabilização do ofensor, em detrimento das ações de atendimento e proteção à vítima.

Para o Conselho Federal de Psicologia, a legislação deixa de dialogar com outras regulamentações existentes nas áreas de políticas de saúde e assistência social, violando os direitos fundamentais de crianças e adolescentes, vistos como simples objetos para a colheita de provas. Além disso, o órgão de classe é contrário à participação de psicólogos no depoimento especial, ao argumento de que o profissional ficaria em posição de mero coletor de provas a serviço do juízo, atribuição incompatível com as suas funções e com a ética profissional. (CONSELHO FEDERAL DE PSICOLOGIA, 2018. p. 3; 8)

No mesmo sentido, posiciona-se o Conselho Federal de Serviço Social, entendendo que a Lei 13.431/17 desconsidera os fundamentos da teoria da proteção integral, por ignorar as responsabilidades da rede de proteção, submetendo o atendimento dos direitos de crianças e adolescentes à jurisdicionalização, o que representaria uma contrarreforma ao Estatuto da Criança e do Adolescente (MATOS, 2019, p. 5).

O referido órgão entende, ainda, que os casos de violência sexual intrafamiliar deveriam envolver, como providências principais, o atendimento e proteção da vítima, por meio de ações articuladas e intersetoriais. A nova legislação, em contrapartida, desviaria a atenção para a responsabilização do agressor. De igual sorte, o Conselho Federal de Serviço Social posicionase contrariamente à participação de assistentes sociais no depoimento especial, por entender que isso extrapolaria as competências e finalidades da sua atuação profissional. (MÖLLER, DINIZ, 2018, p. 5-6; 15)

Não se olvida que crianças e adolescentes têm o direito de ser ouvidas em processos judiciais que digam respeito aos seus interesses. Nesse sentido, há previsão expressa no artigo 12 da Convenção sobre os Direitos da Criança. É com base nessa previsão, inclusive, que alguns defendem a necessidade da escuta judicial em processos que versem sobre violência sexual intrafamiliar. (CEZAR, 2014, p. 260).

No entanto, a presença da criança ou adolescente em processos da justiça deve ocorrer sempre que ela desejar, e não como uma imposição, sob pena de confundir-se a garantia de 
participação e expressão da opinião em feitos judiciais com o dever de produzir provas, mesmo que contra a sua vontade. (AZAMBUJA, 2013, p. 502).

Exigir da criança ou adolescente que participe de um processo com o objetivo de angariar provas para uma possível condenação do acusado, ainda que observadas as diretrizes legais, é ato potencialmente violador de direitos, dada a sua condição de sujeito em desenvolvimento.

\section{CONCLUSÃO}

Da análise realizada na presente pesquisa, conclui-se que os procedimentos diferenciados de oitiva judicial previstos na Lei 13.431/17 não asseguram a proteção integral de direitos de crianças e adolescentes vítimas de violência sexual intrafamiliar.

Com a consolidação da teoria da proteção integral, o ordenamento jurídico brasileiro conferiu especial proteção às crianças e adolescentes, dada a sua condição de sujeitos em desenvolvimento. À família, à sociedade e ao Estado foi atribuído o dever de colocar crianças e adolescentes a salvo de qualquer tipo de violência.

Um conjunto de normas e princípios fornecem proteção jurídica contra a violência sexual envolvendo crianças e adolescentes, ao mesmo tempo em que preveem mecanismos de enfrentamento a essas práticas, determinando ao Poder Público que implemente políticas públicas interdisciplinares com tal finalidade.

A despeito dessa proteção, o problema da violência sexual contra crianças e adolescentes está longe de ser superado, sendo atribuído a fatores diversos, dentre os quais se destaca o resquício de um padrão cultural que colocava a criança em posição de submissão com relação aos adultos. Essa violação gera consequências devastadoras às vítimas, sujeitos sem maturidade suficiente para compreender o ato.

Dados evidenciam que uma parcela considerável da violência sexual perpetrada contra a crianças e adolescentes ocorre no ambiente intrafamiliar, o acaba dificultando a identificação 
da violação. Isso porque, não bastasse esse tipo de violência nem sempre deixar vestígios, a natureza da relação entre vítima e agressor diminui a probabilidade de que haja denúncia.

Em razão dessas dificuldades probatórias, o sistema de justiça, responsável pelas ações de controle e responsabilização envolvendo a violência, dá valor especial à palavra da vítima.

A Lei 13.431/17, ao normatizar os procedimentos de oitiva judicial de crianças e adolescentes vítimas de violência, acaba legitimando a participação obrigatória destas nos processos judiciais, no qual assumem importante função para a fase de colheita de provas. Com isso, veem-se coagidas a prestar depoimentos que, inexoravelmente, as farão reviver a traumática situação de violência pela qual passaram.

Constata-se, assim, que o depoimento especial gera vitimização secundária, produzida institucionalmente pelo sistema de justiça na busca por provas. A criança ou adolescente, que não possui maturidade para compreender e internalizar a violência sexual pela qual passou, será submetida a uma nova violação, por meio da exigência para que revisite o passado e explique a dinâmica dos acontecimentos.

A despeito do intuito protetivo da Lei 13.431/17, que objetiva minimizar os danos impostos à população infantojuvenil no bojo de processos judiciais em que se apura a prática da violência, seu desiderato não é adequadamente cumprido.

Com a análise dos estudos sobre o tema, verifica-se que a adoção de providências tendentes à humanização do ato, realizado em ambientes acolhedores e com a participação de profissionais especializados, não elimina completamente os riscos de danos, especialmente psicológicos. Ademais, prestar o depoimento deveria ser uma faculdade, corolário da garantia de participação e expressão da vontade prevista na Convenção de Direitos da Criança, e não uma imposição.

Para o enfrentamento da violência sexual intrafamiliar contra crianças e adolescentes, é necessário articular estrategicamente políticas públicas interdisciplinares nos diferentes níveis do Sistema de Garantia de Direitos, com foco nas ações preventivas de sensibilização, atendimento e, por fim, proteção, para que a criança ou adolescente seja posta a salvo da situação da violência. 
Ainda que o sistema de justiça seja igualmente importante, sua atuação deve ocorrer de forma integrada e complementar com os demais órgãos, voltando-se à efetivação dos direitos da criança e do adolescente, tendo em vista o reordenamento institucional decorrente da adoção da teoria da proteção integral.

A Lei 13.431/17, ao contrário, prioriza a responsabilização do acusado. Com isso, jurisdicionaliza o atendimento e permite que a criança ou adolescente figure como um objeto a serviço do Poder Judiciário, o que viola os direitos fundamentais e a condição peculiar de pessoa em desenvolvimento de crianças e adolescentes constituindo retrocesso com relação à teoria da proteção integral.

\section{REFERÊNCIAS}

AZAMBUJA, Maria Regina Fay de. A interdisciplinaridade na violência sexual. Serviço. Social e Sociedade., São Paulo, n. 115, p. 487-507, setembro de 2013. Disponível em: https://www.scielo.br/scielo.php?script=sci_arttext\&pid=S0101-66282013000300005 Acesso em: 05 jul. 2020.

AZAMBUJA, Maria Regina Fay de. Violência sexual intrafamiliar: interfaces com a convivência familiar, a oitiva da criança e a prova da materialidade. Revista dos Tribunais, São Paulo: RT, vol. 852/2006, p. 424/466.

BITENCOURT, LUCIANE POTTER. A vitimização secundária de crianças e adolescentes $e$ a violência sexual intrafamiliar. Dissertação (Mestrado em Direito). Programa de Pósgraduação em Direito, Pontifícia Universidade Católica do Rio Grande do Sul, Porto Alegre, 2007. Disponível em: https://repositorio.pucrs.br/dspace/handle/10923/1713. Acesso em: 05 jun. 2020.

BRASIL. Constituição da República Federativa do Brasil (1988). Disponível em: http://www.planalto.gov.br/ccivil_03/constituicao/constituicaocompilado.htm. Acesso em: 5 jun. 2020.

BRASIL. Lei n. 2.848, de 07 de dezembro de 1940. Código Penal. Disponível em: http://www.planalto.gov.br/ccivil_03/decreto-lei/del2848compilado.htm. Acesso em: 5 jun. 2020.

BRASIL. Decreto n. 99.710, de 21 de novembro de 1990a. Promulga a Convenção sobre os Direitos da Criança. Disponível em: http://www.planalto.gov.br/ccivil_03/decreto/19901994/d99710.htm. Acesso em: 05 jun. 2020. 
BRASIL. Lei n. 8.069, de 13 de julho de 1990b. Dispõe sobre o Estatuto da Criança e do Adolescente e dá outras providências. Disponível em: http://www.planalto.gov.br/ccivil_03/leis/18069.htm. Acesso em: 05 jun. 20.

BRASIL. Lei n. 13.010, de 26 de junho de 2014. Altera a Lei $n^{\circ} 8.069$, de 13 de julho de 1990 (Estatuto da Criança e do Adolescente), para estabelecer o direito da criança e do adolescente de serem educados e cuidados sem o uso de castigos s ou de tratamento cruel ou degradante, e altera a Lei $\mathrm{n}^{\circ}$ 9.394, de 20 de dezembro de 1996. Disponível em: http://www.planalto.gov.br/ccivil_03/_ato2011-2014/2014/lei/113010.htm. Acesso em: 05 jun. 2020.

BRASIL. Lei n.13.431, de 4 de abril de 2017. Estabelece o sistema de garantia de direitos da criança e do adolescente vítima ou testemunha de violência e altera a Lei $\mathrm{n}^{\circ} 8.069$, de 13 de julho de 1990 (Estatuto da Criança e do Adolescente).Disponível em: http://www.planalto.gov.br/ccivil_03/_ato2015-2018/2017/lei/113431.htm. Acesso em: 05 jun. 2020.

BRASIL. Ministério da Mulher, da Família e dos Direitos Humanos. Disque Direitos Humanos: Relatório 2019. Brasília, maio de 2020. Disponível em: http://www.crianca.mppr.mp.br/arquivos/File/publi/mmfdh/disque_100_relatorio_mmfdh201 9.pdf. Acesso em: 25 jun. 2020.

BRASIL. Ministério Da Saúde. Violência intrafamiliar: orientações para prática em serviço. Brasília: Secretaria de Políticas de Saúde, 2002. Disponível em: https://bvsms.saude.gov.br/bvs/publicacoes/cd05_19.pdf. Acesso em 05 jul.2020. Acesso em 25 jun. 2020.

CONSELHO FEDERAL DE PSICOLOGIA. Nota técnica sobre os impactos da Lei 13.431/2017 na atuação das psicólogas e dos psicólogos. Brasília, 2018. Disponível em: https://crp04.org.br/cfp-publica-nota-tecnica-sobre-a-lei-que-institui-depoimento-especial-decriancas-e-adolescentes/. Acesso em: 5 jul. 2020.

CONSELHO FEDERAL DE SERVIÇO SOCIAL. Nota sobre a Resolução 299/2019 do CNJ. 2020. Disponível em: http://www.cfess.org.br/arquivos/nota-CNJ-cfess-2020.pdf. Acesso em 25 jun. 2020.

CONSELHO NACIONAL DE JUSTIÇA. Recomendação $n^{\circ} 33$, de 23 de novembro de 2010. Recomenda aos tribunais a criação de serviços especializados para escuta de crianças e adolescentes vítimas ou testemunhas de violência nos processos judiciais. Depoimento Especial. Disponível em: https://atos.cnj.jus.br/files//recomendacao/recomendacao_33_23112010_22102012173311.pd f. Acesso em: 05 jun. 2020

CONSELHO NACIONAL DE JUSTIÇA. Resolução $n^{o} 299$ de 05/11/2019. Dispõe sobre o sistema de garantia de direitos da criança e do adolescente vítima ou testemunha de violência, de que trata a Lei $\mathrm{n}^{\circ}$ 13.431, de 4 de abril de 2017. Disponível em: https://atos.cnj.jus.br/files/original000346201912045de6f7e29dcd6.pdf. Acesso em: 05 jun. 2020 
CUSTÓDIO, André Viana. Teoria da proteção integral: pressuposto para compreensão do direito da criança e do adolescente. Revista do Direito UNISC, Santa Cruz do Sul, n. 29 janeiro/junho de 2008. p. 22-43, disponível em: https://online.unisc.br/seer/index.php/direito/article/view/657. Acesso em: 05 jun. 2020.

CUSTÓDIO, André Viana; MOREIRA, Rafael Bueno da Rosa. O papel das políticas públicas na promoção de ações de sensibilização sobre violência sexual contra crianças e adolescentes. Revista Direito \& Paz, Unisal: São Paulo. V. 2, n. 41, 2019, p. 123-144.

CUSTÓDIO, André Viana; REIS, Suzéte da Silva. Fundamentos históricos e principiológicos do direito da criança e do adolescente: bases conceituais da teoria da proteção integral. Revista Justiça do Direito, v. 31, n. 3, 2017, p. 621-659. Disponível em: http://seer.upf.br/index.php/rjd/article/view/7840. Acesso em: 05 jun. 2020.

CEZAR, José Antônio Daltoé. A atenção à criança e ao adolescente no judiciário: práticas tradicionais em cotejo com práticas não revitimizantes (depoimento especial). In: SANTOS, Benedito Rodrigues dos; GONÇALVES, Itamar Batista; VASCONCELOS, Gorete. Escuta de crianças e adolescentes em situação de violência sexual: aspectos teóricos e metodológicos: guia para capacitação em depoimento especial de crianças e adolescentes. Brasília: EdUCB, 2014. Disponível em: http://www.crianca.mppr.mp.br/2015/10/12202,37/. Acesso em: 05 jun. 2020.

DIAS, Felipe da Veiga; CHAVES, Patrícia Adriana. A teoria da proteção integral como pressuposto de análise para violência intrafamiliar contra a criança e o adolescente no Brasil. In: CUSTÓDIO, André Viana; DIAS, Felipe da Veiga; RIES, Suzéte da Silva. Violência intrafamiliar contra crianças e adolescentes: proteção integral e políticas públicas. Curitiba: Multideia, 2016, p. 53-70.

FALEIROS, Vicente de Paula. Abuso sexual de crianças e adolescentes: trama, drama e trauma, Serviço Social e Saúde, Campinas, v. 2, n. 1, p. 65-82, jan. 2005. Disponível em: https://periodicos.sbu.unicamp.br/ojs/index.php/sss/article/view/8636441. Acesso em: 25 jun. 2020.

KRUG, Etienne G.; DAHLBERG, Linda L.; MERCY, James A.; ZWI, Anthony B.; LOZANO, Rafael. Relatório mundial sobre violência e saúde. Genebra: OMS, 2002. Disponível em: https://www.cevs.rs.gov.br/upload/arquivos/201706/14142032-relatorio-mundial-sobreviolencia-e-saude.pdf. Acesso em: 5 jul. 2020.

KÜHL, Franciele Letícia. Políticas públicas de atendimento às crianças e adolescentes vítimas de abuso sexual intrafamiliar: uma análise no município de Santa Cruz do Sul no período de 2014 a 2018. Dissertação (Mestrado em Direito). Programa de Pós-graduação em Direito, Universidade de Santa Cruz do Sul, Santa Cruz do Sul, 2018. Disponível em: https://repositorio.unisc.br/jspui/handle/11624/2435. Acesso em: 25 jun. 2020.

MATOS, Maurílio Costa de. Nota Técnica sobre a "escuta especializada" proposta pela Lei 13.431/2017: questões para o Serviço Social. Conselho Federal de Serviço Social (CFSS). 2019. Disponível em: http://www.cfess.org.br/arquivos/Nota-tecnica-escuta-especial2019.pdf. Acesso em: 05 jun. 2020. 
MÖLLER, Daniela; DINIZ, Tânia Maria Ramos de Godoi. Nota Técnica sobre o exercício profissional de assistentes sociais e as exigências para a execução do Depoimento Especial. Conselho Federal de Serviço Social (CFSS). 2018. Disponível em: http://cress-ce.org.br/wpcontent/uploads/2019/06/depoimento-especial-notatecnica2018-1.pdf. Acesso em: 05 jun. 2020.

MOREIRA, Rafael Bueno da Rosa; Jesus, Ana Paula da Costa de. A violência sexual contra crianças e adolescentes no Brasil: da proteção jurídica às políticas públicas. In: Seminário Internacional Demandas Sociais e Políticas Públicas na Sociedade Contemporânea: Mostra Internacional de Trabalhos Científicos. 2015, Santa Cruz do Sul. Anais eletrônicos. Santa Cruz do Sul: $\quad$ EDUNISC, $2015 . \quad$ Disponível em: https://online.unisc.br/acadnet/anais/index.php/sidspp/article/view/13166

MOREIRA, Rafael Bueno da Rosa; REIS, Suzete da Silva. A violência intrafamiliar contra crianças e adolescentes: das causas e consequências. In: CUSTÓDIO, André Viana; DIAS, Felipe da Veiga; RIES, Suzéte da Silva. Violência intrafamiliar contra crianças e adolescentes: proteção integral e políticas públicas. Curitiba: Multideia, 2016, p. 71-94.

PEREIRA JÚNIOR, Antônio Jorge; REBOUÇAS, Marícula Bitencourt Calou; PEREIRA, Marynna Laís Quirino. Protocolos de oitiva especial de criança segundo a Recomendação 33 do Conselho Nacional de Justiça e a Lei 13.431, de 5 de abril de 2017, Revista dos Tribunais, São Paulo: RT, Vol. 933/2018, p. 403-420.

SANTOS, Adriana Ribeiro dos; COIMBRA, José César. O Depoimento Judicial de Crianças e Adolescentes entre o Apoio e a Inquirição. Revista Psicologia: Ciência e Profissão, vol. 37, $\mathrm{n}^{\circ}$ 3, jul-set/2017, p. 595-607, Disponível em: https://www.scielo.br/pdf/pcp/v37n3/1982-3703pcp-37-3-0595.pdf Acesso em: 5 jun. 2020.

SOUZA, Ismael Francisco. O reordenamento do programa de erradicação do trabalho infantil (PETI): estratégias para concretização de políticas públicas socioassistenciais para crianças e adolescentes no Brasil. 2016. Tese (Doutorado em Serviço Social) - Universidade de Santa Cruz do Sul - UNISC, 2018. Disponível em: https://repositorio.unisc.br/jspui/bitstream/11624/1304/1/Ismael\%20Francisco\%20de\%20Sou za.pdf. Acesso em 2 de julho de 2020.

VERONESE, Josiane Rose Petry. A proteção integral da criança e do adolescente no direito brasileiro. Revista do Tribunal Superior do Trabalho, São Paulo, v. 79, n. 1, p. 38-54, jan./mar. 2013

WAISELFISZ, Julio Jacobo. Mapa da violência 2012: Crianças e Adolescentes do Brasil. Rio de Janeiro: Cebela, 2012. Disponível em: http://www.crianca.mppr.mp.br/arquivos/File/publi/xtras/mapaviolencia2012_criancas_e_ado lescentes.pdf. Acesso em 25 jun. 2020

Data de Submissão: 10/08/2020

Data de Aceite: $24 / 11 / 2020$ 